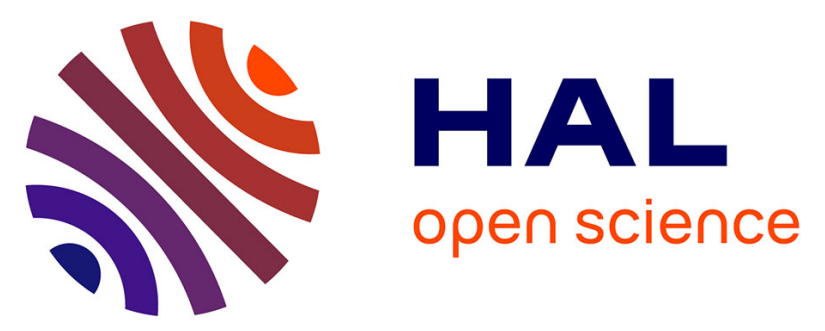

\title{
Characterizing the spatial and temporal variability of biophysical variables of a wheat crop using hyper-spectral measurements
}

Sophie Moulin, R. Zurita Milla, Martine Guerif, Frédéric Baret

\section{- To cite this version:}

Sophie Moulin, R. Zurita Milla, Martine Guerif, Frédéric Baret. Characterizing the spatial and temporal variability of biophysical variables of a wheat crop using hyper-spectral measurements. IEEE international geoscience and remote sensing symposium, Jul 2003, Toulouse, France. 10.1109/IGARSS.2003.1294390 . hal-02763095

\section{HAL Id: hal-02763095 \\ https: / hal.inrae.fr/hal-02763095}

Submitted on 4 Jun 2020

HAL is a multi-disciplinary open access archive for the deposit and dissemination of scientific research documents, whether they are published or not. The documents may come from teaching and research institutions in France or abroad, or from public or private research centers.
L'archive ouverte pluridisciplinaire HAL, est destinée au dépôt et à la diffusion de documents scientifiques de niveau recherche, publiés ou non, émanant des établissements d'enseignement et de recherche français ou étrangers, des laboratoires publics ou privés. 


\title{
Characterizing the Spatial and Temporal Variability of Biophysical Variables of a Wheat Crop Using Hyper- spectral Measurements
}

\author{
S. Moulin, R. Zurita Milla, M. Guérif and F. Baret \\ INRA - Unité Climat, Sol, et Environnement (CSE) \\ Bât. Climat - Site Agroparc - Domaine Saint-Paul, \\ 84914 Avignon cedex 9 , France
}

\begin{abstract}
The spatial extension to field scale of biophysical variables retrieval from radiometric measurements is addressed. Hyper-spectral measurements were acquired over a wheat field at 4 dates in 2000 with a CASI sensor. In 2002, XYBION multispectral sensor ( 6 bands) was used to acquire images at 5 dates. For each year, ground measurements were performed at ground level to estimate green LAI and Cab. Two methods of retrieving biophysical variables were tested. The inversion through radiative transfer modeling was used with hyperspectral measurements, whereas empirical relationships were used to estimate variables from XYBION data. The results were discussed in terms of spatial and temporal variations of the estimates.
\end{abstract}

\section{Keywords-precision farming; biophysical variables}

\section{INTRODUCTION}

The characterization of the crop status is of first importance in agriculture. When dealing with precision farming, one has to monitor the vegetation with a high spatial resolution to account for within field spatial heterogeneities. Airborne radiative measurements can help us with characterizing the crop at field scale with a tight spatial resolution (1 meter). In particular, through inversion of radiative transfer model with hyperspectral measurements [1], biophysical variables such as green leaf area index (gLAI) and leaf chlorophyll content (Cab) were estimated.

The first objective of the paper was to test the feasibility of making operative use of an airborne multi-spectral video camera to estimate gLAI, Cab and canopy chlorophyll content (LAI*Cab). The second objective was to provide mapping at field scale of pertinent biophysical variables for precision farming applications and to check the reliability of the variables time profiles along the growing season.

\section{MATERIAL}

In the frame of a precision farming project, an experiment was conducted [2] aiming at assessing the nitrogen status of a wheat crop.

\section{A. Airborne measurements}

Two airborne sensors were used to acquire images of the field. In 2000, images were acquired with a Compact Airborne Spectrographic Imager (CASI, ITRES, Canada) onboard a plane flying at a $1500 \mathrm{~m}$ altitude and providing data in 32 spectral bands of $10 \mathrm{~nm}$ width in the $350-1050 \mathrm{~nm}$ range with a ground spatial resolution of $2 \mathrm{~m}$. Images were acquired in sunny sky conditions around 12:00 HTU. CASI images were available for 4 dates during the wheat growing period. The data were corrected from atmospheric effects using ground reference targets. In 2002, the XYBION Multispectral Video Camera MSC-02 (Xybion Inc., CA), an airborne sensor equipped with a charge-coupled device (CCD), was used. It provided a spectral coverage from 0.4 to $1.1 \mathrm{~m}$ with 6 filters covering the visible and near infrared domains. Five flights were performed (1500m altitude) with the XYBION camera from March to July 2002 to cover the whole winter wheat cycle. As the calibration of the XYBION data is not yet operational, raw data were used in this study.

\section{B. Biological measurements}

Some ancillary data (gLAI and Cab) were collected around the flight dates in order to calibrate and validate the estimations. Measurements of LAI were performed using a LICOR $^{\circledR} \quad$ LAI-2000 and chlorophyll concentration was estimated with Hydro N-tester device. For a given date, 20 to 80 points of measurements were realized on a $1 \mathrm{~m}^{2}$ surface. The relation between $\mathrm{N}$-tester measures and $\mathrm{Cab}$ on one hand and between LAI-2000 measures and gLAI on the other hand where calibrated thanks to destructive measurements.

In order to study the relative influence of soil and fertilization conditions on the within field heterogeneity, different nitrogen fertilization treatments were performed during the 2002 campaign. The field was divided into 9 zones where 3 levels of fertilizers were applied in 4 doses along the wheat cycle.

\section{METHOD}

Depending on the quality of pre-processing of the airborne measurements, 2 different methods were used to estimate 
biophysical variables. Empirical relationships and physically based method were used for XYBION and CASI data, respectively.

\section{Empirical methods}

Biophysical variables estimation was performed using vegetation indices computed from digital numbers acquired in the 6 XYBION bands. Empirical relationships were built using $70 \%$ of the ground truth data (calibration subset) randomly chosen. All the dates were mixed, as the variability for one given date was too small to find a trend. Relationships were established with several vegetation indices.

\section{Model inversion}

Models describing the radiative transfer in the crop (SAIL [3]) and in the leaf (PROSPECT [4]) were used to simulate the crop radiometric signature. For a given acquisition date, one can simulate the radiometric signal provided that input parameters are known. Conversely, the parameters can be estimated by matching the simulation with the observed reflectances. This inversion was realized through an iterative process that aims at adjusting model input parameters by minimizing a merit function generally based on the distance between observed and simulated reflectances. This technique was improved by introducing a prior knowledge on the searched variables in the merit function (see [1]).
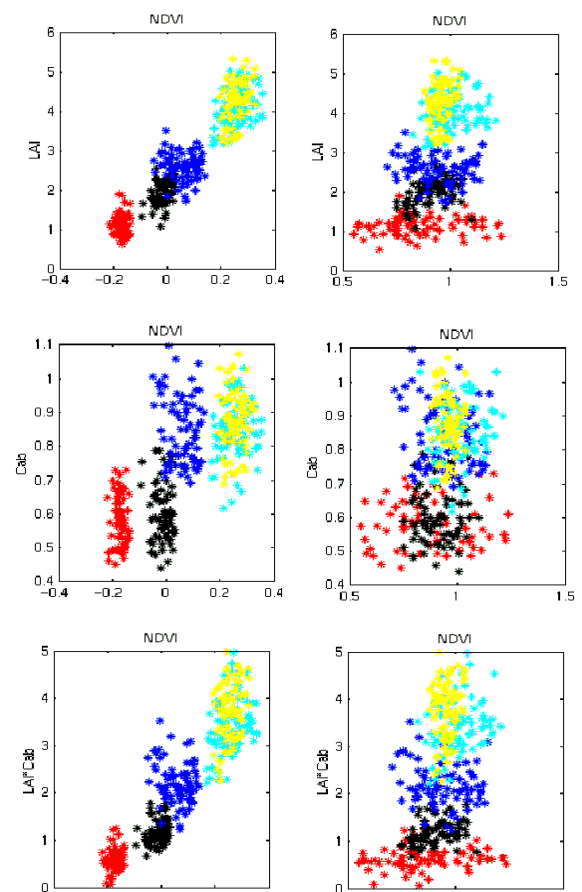

1

gLAI, Cab and gLAI x Cab estimates from XYBION NDVI

\section{RESUlts}

\section{E. Empirical estimation with XYBION 2002 data}

Fig 1. shows the scatter plot of variables (gLAI, Cab and gLAI x Cab) versus NDVI [5]. From comparison between the estimated and the measured biophysical variables, some conclusions can be drawn. Most of the relationships were linear. The near-infrared/red ratio yielded the best $\mathrm{r}^{2}$ values for estimation of the 3 variables. SAVI [6] family of vegetation indices has the strongest predictive power in terms of gLAI estimation (lowest rmse). Weaker relationships were found for Cab in terms of $r^{2}$. Surprisingly, soil resistant vegetation indices seemed sensitive to Cab and provided better $\mathrm{r}^{2}$ than specific indices. The rmse on estimated gLAI using XYBION data was about 0.5 .

The ground data were in agreement with the spatial distribution of nitrogen nutrition levels (ANOVA test), however the spatial distribution of estimated variables from XYBION at field level did not yield satisfactory results. Moreover, for a given date, no trend was established due to a weakness in the ground sampling strategy.

\section{F. Spatial variations with CASI 2000 data}

The inversion was run for each pixel of the images. We obtained a retrieved set of variables that can be represented as maps. As an example, Fig. 2 shows the spatial distribution obtained for gLAI and Cab product on 8th April 2000. The spatial resolution was reduced from $2 \mathrm{~m}$ to $20 \mathrm{~m}$ to decrease the computing time. The map shows a strong within field variability in terms of canopy chlorophyll content. The absolute validation of the estimation is a tricky task since ground measurement sampling (about 1 square meter) was not representative of a pixel. Moreover, an error is associated to the geographic localization of on one hand the points of measurements and on the other hand the pixel images due to geo-referencing process. The precision of retrieval was estimated to 1.3 for gLAI (on a 1 to 7 range) and $6 \mu \mathrm{g} / \mathrm{cm}^{2}$ for Cab (on a 40 to 70 range). This precision may not be good enough to elaborate a spatially modulate technique for fertilization purpose based on the absolute estimates. However, the use of relative information by defining zoning that would required more or less fertilizer compared with a reference dose could be relevant.
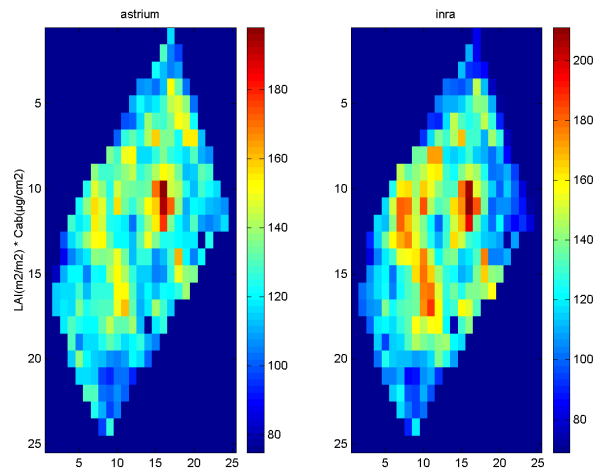

2 Mapping of the gLAI and Cab product using CASI $\left(\mu \mathrm{g} / \mathrm{cm}^{2}\right)$

The spatial distribution was compared with the soil brightness index computed from red and near-infrared wavebands of an image acquired before the emergence of any vegetation (Fig. 3) as well as with the soil map (Fig. 4). Calcosol seems to 


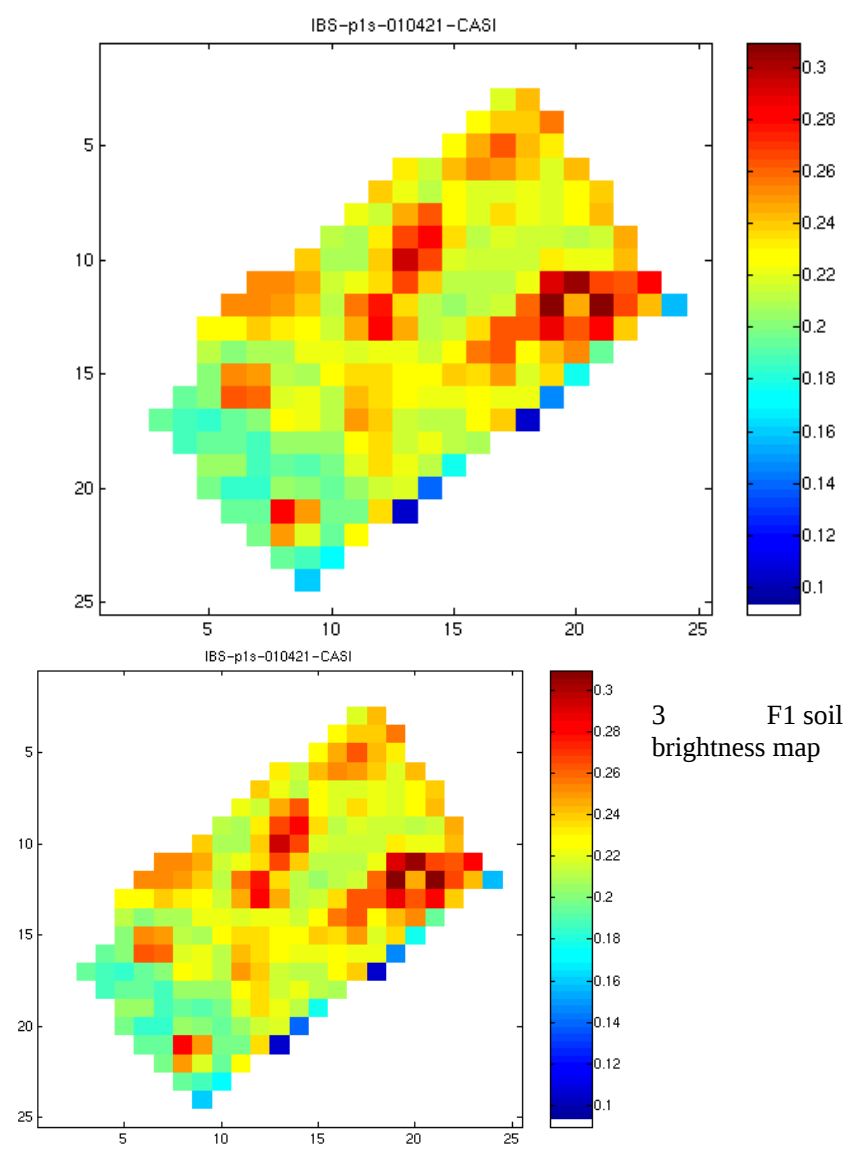

$4 \quad$ : F1 soil map

correspond to highest soil brightness values and lowest plant chlorophyll concentration (represented here by the Cab and gLAI product).

\section{G. Temporal variations with CASI 2000 data}

The inversion was performed for the 4 acquisition dates. To evaluate the temporal consistency of the results, we compared model and measurements on the ground characterized points. For a given date, the measured gLAI and Cab were averaged on the whole points (20 to 80 points). A spatial extraction of the spectra was realized for each point and each date (9 pixels surface). The spectra were used through inversion to estimate gLAI and Cab on the groundcharacterized points. The comparison between spatially averaged estimates and measurements were plotted on Fig. 5 and Fig. 6. The figures show that the general time variations across the growing season between the estimated and measured variables are in agreement although we notice an over-estimation in the estimates. The estimates in terms of rmse are not very accurate especially for gLAI with a rmse of $1.24 \mathrm{~m}^{2} / \mathrm{m}^{2}$ and $5.9 \mu$ g.cm- ${ }^{2}$ for Cab due to the poor ground sampling.

\section{CONCLUSION}

XYBION sensor showed ability in estimating the gLAI using empirical relations through vegetation indices. Moreover, we noticed that the product of gLAI and Cab was better estimated than Cab. The product, which represents the plant chlorophyll content, is also more easily related to the plant nitrogen status. A first validation was obtained by comparing the global temporal profiles of CASI estimates to the measured temporal profiles. Concerning the spatial zoning, some similar features were obtained when comparing with soil map but the validation needs further investigations.
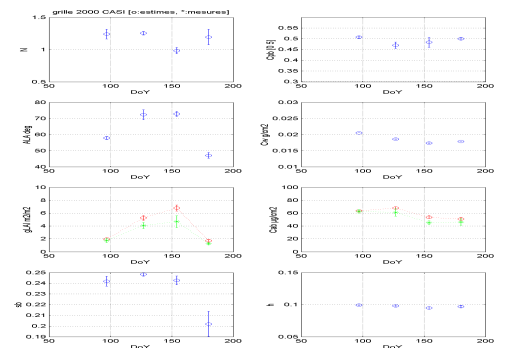

5

gLAI temporal profile: data (*), prediction (o)

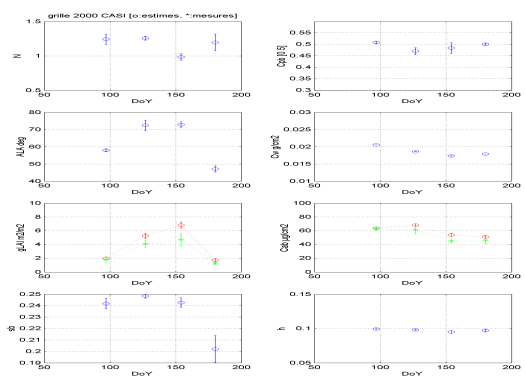

$6 \quad$ Cab temporal profile: data $\left(^{*}\right)$, prediction (o)

\section{ACKNOWLEDGMENT}

Astrium is acknowledged for providing CASI data.

\section{REFERENCES}

[1] Moulin S., Guérif M., Baret F., Retrieval of biophysical variables on Ntreatments of a wheat crop using hyperspectral measurements, 2003, International Geoscience and Remote Sensing Symposium, 21-25 July 2003, Toulouse, France, abstract, this issue.

[2] Guérif M, N. Beaudoin, C. Durr, J.M. Machet, B. Mary, D. Michot, S. Moulin, B. Nicoullaud, G.Richard, 2001, Designing a field experiment for assessing soil and crop spatial variability and defining site specific management strategies. Third European Conference on Precision Farming, 18-20 June 2001 - Montpellier, France, 677-682.

[3] Verhoef, W., 1984, Light scattering by leaf layers with application to canopy reflectance modeling : the SAIL model. Remote Sens. Environ., 16:125-141.

[4] Jacquemoud S. and Baret F., 1990, PROSPECT : a model of leaf properties, Remote Sens. Environ., 34:75-91.

[5] Rouse, J. W., Haas, R.H., Schell, J.A., Deering, D.W. and Harlan, J.C. (1974). Monitoring the vernal advancement of retrogradation of natural vegetation. NASA/ GSFC, Type III, Final Report, Greenbelt, MD, USA. $1-371$. 
[6] Huete, A. R. (1988). A soil-adjusted vegetation index (SAVI). Remote Sens. Environ. 25, 295-309.
[7] Kuusk, A., 1991, The hot spot effect in plant canopy reflectance, in Photon-vegetation interactions. Applications in optical remote sensing and plant ecology, Myneni and Ross eds, Springer Verlag, pp 139-159. 
